\title{
Variations of low temperature fumaroles as a tool for detecting changes in volcanic activity state: a brief overview
}

\author{
Paolo Madonia \\ Istituto Nazionale di Geofisica e Vulcanologia, Sezione di Roma 2, via di Vigna Murata 605, 00143 Roma, Italia
}

Correspondence: Paolo Madonia (paolo.madonia@ingv.it)

Received: 10 June 2020 - Revised: 6 October 2020 - Accepted: 30 October 2020 - Published: 24 November 2020

\begin{abstract}
Fumarolic fields, especially those with nearsurface soil temperature $<100^{\circ} \mathrm{C}$, are very common features of active or quiescent volcanoes, with both open or closed conduits. Their spatial extent, as well as the time variability of their temperature, are conditioned by three main factors: (1) Local hydro-meteorological conditions; (2) Vapor flow from the underlying volcanic-hydrothermal system; (3) Permeability variation induced by stress field changes and/or deposition dissolution cycles of hydrothermal alteration minerals. Once depurated from the exogenous noise, time variations of the thermal signal, in term of both short-lasting transients and medium/long term trends, reflect changes in the activity state of the related volcanic system, and/or of seismic activity, also of tectonic origin, affecting volcanoes. Theoretical models of heat transfer processes are discussed, highlighting how it is very difficult distinguish between conductive and convective mechanisms or calculating heat fluxes: as a consequence, thermal data from low temperature fumaroles should be used as qualitative proxies of volcano-tectonic phenomena acting on the monitored volcanoes.

Following the description of the measuring systems and of the criteria for designing a performing network for thermal monitoring of fumaroles, some case histories from Italian volcanoes (Vulcano, Stromboli, Mt. Etna, Mt. Vesuvius) are presented, illustrating how in the last years the monitoring of low temperature fumaroles have given useful insights on the evolution of the activity state of these volcanoes.
\end{abstract}

\section{Introduction}

Fumaroles can be defined as portions of the Earth's surface venting water as a volatile (gas and/or vapour), eventually associated to other chemical species, at temperatures higher than the ambient ones, and are typical of volcanic and/or hydrothermal areas. The monitoring of their space and time variations is often used in volcanic surveillance programs. While ascending towards the Earth's surface magma releases significant amounts of water, causing increases of both temperature and areal extension of fumarolic fields. Among the others, examples are from Mt. Etna (Madonia et al., 2013), Stromboli (De Gregorio et al., 2007; Madonia and Fiordilino, 2013), Vulcano island (Bukumirovic et al., 1997; Cannata et al., 2011).

Conversely, the opposite phenomena (temperature decrements and reduction of exhaling areas) are observed when volcanic activity progressively vanishes.

These features can be subdivided into High or Low Temperature Fumaroles (hereafter referred as HTF and LTF) depending on whether their venting temperatures are higher or lower than the boiling temperature of water at the vent altitude.

HTF and LTF have very different physical-chemical properties, which are reflected in their suitability for the monitoring of volcanic activity. In HTF water is at the vapour/gas state during the entire transfer process from the magmatic/hydrothermal source to the Earth's surface, with important implications for their thermal regime and chemicalisotopic composition. The absence of the liquid phase does not limit the upgoing dynamic of their temperature: as an example, during the 1988 unrest phase the main fumarolic field of La Fossa cone, at Vulcano island, reached the maximum temperatures of $474{ }^{\circ} \mathrm{C}$ (Badalamenti et al., 1991). Moreover, the chemical and isotopic composition of HTF is not affected by any modification: in a monophasic system there is no isotopic fractionation and no separation of hydrophilic acidic species, as $\mathrm{HF}$ or $\mathrm{HCl}$, which are preferentially enriched in the liquid water resulting from the vapor condensa- 
tion (Madonia et al., 2019). The disadvantage in using HTF for monitoring activities is the short technical life of the sensors, subjected to high thermal stress and fast corrosion, fostered by the contact with strongly acidified meteoric water (rain, condensing atmospheric moisture).

On the other hand, because of the coexistence of the liquid and vapor phases, LTF have a compressed thermal dynamic, whose upper limit is determined by the boiling temperature of water at the vent altitude; they can evolve in HTF if there is a notable increment in the energetic state of a volcano, in consequence of which all the liquid water in the shallower portion of the feeding system of a fumarolic field is transformed in vapor. LTF are not representative of the chemical and isotopic character of the hydrothermal source, because the partial condensation of water causes isotopic and chemical fractionations. The advantage in their use, for monitoring purposes, is the longer technical life of the sensors and their wider geographical distribution. LTF are more common than HTF because of the lower energetic state required for their existence: this condition is found also in quiescent volcanic system, as Mt. Vesuvius or the Greek islands of Santorini and Milos.

The thermal regime of LTF is determined by the variable mixing between hydrothermal and shallow meteoric components, driven by (1) variations of the magmatic-hydrothermal source, (2) permeability changes induced by stress field variations and (3) variability of the hydrological regime (Madonia et al., 2008, and references therein; Petrosino et al., 2018).

In the next two chapters the theoretical background of heat transfer processes in LTF, and systems and strategies of measure of temperature are described, followed by a short overview on papers published in the last years on the application of this methodology on Italian volcanoes.

\section{Theoretical background of heat transfer processes in LTF}

The main question about the mechanisms of heat transfer acting in LTF is related to the role of conductive and convective processes. The pure conductive model considers that over the condensation level of vapor, e.g. the depth at which the water boiling temperature (hereafter referred as WBT) is reached, heat transfer is basically conductive because the most of the vapor condenses into the soil as liquid water. However, simple field observations like the rapid wetting of any kind of object laid down on the ground in a LTF, seem to indicate that the vapor tension at temperatures also much lower than the WBT $\left(50-60,60^{\circ} \mathrm{C}\right)$ sustains a significant steam flow, and that convection is a relevant, if not dominant, component of heat transfer processes also in the shallowest soil horizons. The conductive heat transfer equation through the soil is of

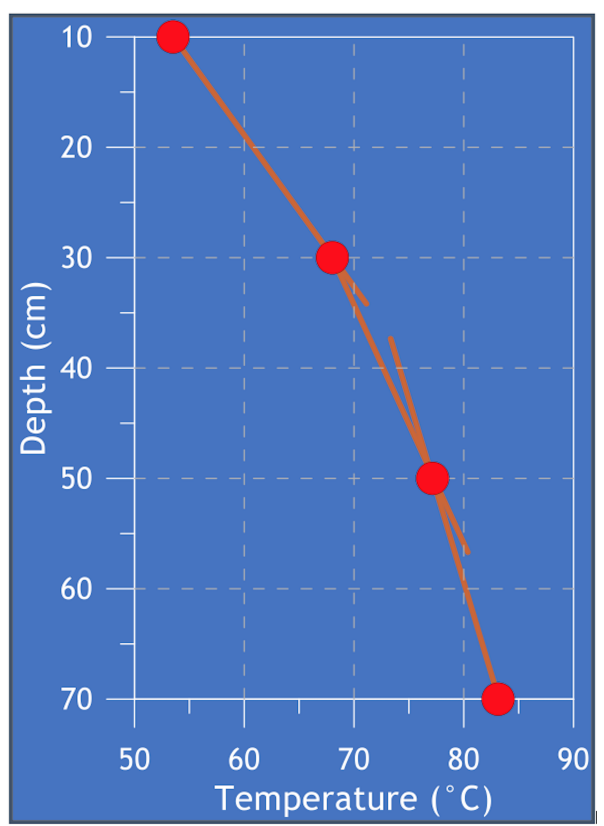

Figure 1. A typical vertical soil temperature profile of a LTF, measured in the summit fumarolic field of Stromboli island.

the type (Incropera and Dewitt, 2002):

$\Phi_{\mathrm{c}}=K_{\mathrm{c}} \times \frac{\left(T_{\mathrm{d}}-T_{\mathrm{s}}\right)}{Z_{\mathrm{d}}-Z_{\mathrm{s}}}$

where $\Phi_{\mathrm{c}}$ is the conductive heat flux, $K_{\mathrm{c}}$ is the thermal conductivity constant conductive heat transfer coefficient, $T_{\mathrm{d}}$ and $T_{\mathrm{s}}$ temperatures measured at two different depths $Z_{\mathrm{d}}$ and $Z_{\mathrm{s}}$, with $Z_{\mathrm{d}}>Z_{\mathrm{s}}$; the sign will be positive for heat fluxes directed towards the surface, and negative for the opposite direction. For the convective mode we have (Incropera and Dewitt, 2002):

$\Phi_{\mathrm{v}}=K_{\mathrm{v}} \times\left(T_{\mathrm{a}}-T_{\infty}\right)$,

where $\Phi_{\mathrm{v}}$ is the convective heat flux, $K_{\mathrm{v}}$ the convective heat transfer coefficient, $T_{\mathrm{a}}$ the temperature of air at the contact with the soli and $T_{\infty}$ the temperature of vented fluids.

A pure convective model is a physical abstraction, because a certain amount of heat is transferred from the vapor to the rocks through which it is vented to the surface. Heat exchanges are relevant if vapor travels through rock pores; on the contrary, if vapor is channelled through open fractures and fast transferred to the surface, the heat exchange can be reduced or negligible at all.

A typical soil temperature vertical profile of a LTF is illustrated in Fig. 1, where measures acquired at 10, 30, 50, $70 \mathrm{~cm}$ of depth in the summit fumarolic field of Stromboli (Aeolian islands, Italy) are reported.

As seen in the figure, a vertical thermal gradient exists, suggesting at a first instance that conduction, more than convection, drives heat transfer. Another evidence is the variable slope of the vertical thermal gradient, indicating that $K_{\mathrm{c}}$ 
Table 1. Typical values of $K_{\mathrm{V}}$ for different convection processes (Incropera and Dewitt, 2002).

\begin{tabular}{llr}
\hline Process & Phase & $K_{\mathrm{V}}$ (Min-Max) \\
\hline Free convection & Gas & $2-25$ \\
Forced convection & Gas & $25-250$ \\
Phase change & Gas, liquid & $2500-100000$ \\
\hline
\end{tabular}

progressively diminishes moving from the depth to the surface: a possible explanation is the progressive decompaction of volcanic deposits, from the depth to the surface, due to the diminution of the load of the overlying materials.

However, an opposite interpretation can be given to the curve of Fig. 1: not a conductive, but a convective model where $K_{\mathrm{v}}$ is not constant but diminishes with the depth due to the variable amount of vapor condensing into the soil: as shown in Table $1, K_{\mathrm{v}}$ experiences large variations if phase transitions occur during convection, with differences greater than four orders of magnitude from the simple free convection to the involvement of phase changes.

The physical congruity of both the conductive and convective models for describing the heat transfer processes in LTF remarks that trying to distinguish between them is captious and, at the same time, that is impossible to quantify heat flux simply measuring temperature along a vertical profile. There are several reasons for affirming this:

- Vapor is always vented to the atmosphere from a LTF, indicating that a pure conductive model is an unrealistic simplification of a more complex system. Moreover, it is really hard to quantitatively measure the residual vapor flux from the surface of a LTF to the atmosphere, mainly because these fluxes are very low and the use of measuring systems will irremediably alter the flux conditions;

- Mass flux and temperature of water vapor condensed into the soil beneath a LTF are unknown, making impossible the quantification of this contribution to the whole heat flux balance;

- It is impossible determining what a probe buried into the soil is measuring with its temperature: how much of the heat transferred to the probe is due to thermal conduction from the rocks and how much from the intersected vapor flux?

The abovementioned considerations drive to the most important assumption in interpreting LTF thermal data: since the quantitative estimation of heat flux is impossible, their variations must be used as a qualitative proxy of changes in the hydrothermal water vapor flux experienced by that fumarolic field. As it will be illustrated in the chapter devoted to the description of study cases from Italian volcanoes, even in absence of quantitative estimations, LTF thermal data can give very useful insights on the evolution of the monitored volcanic systems.

\section{Systems and strategies of LTF temperature measurements}

Temperature is a parameter easily measurable, both in terms of simplicity and reduced costs of the involved hardware, either as spot measurements or adopting automatic datalogging systems. The choice among different kind of thermal sensors and data acquisition systems is really wide, and the description of the best technical solutions is out of the aims of this work. Basically, there are two different systems for temperature measurements: remote sensing via thermal infrared cameras and direct measurements with probes buried into the soil: both systems have vantages and disadvantages. Thermal imaging gives an overall view of a fumarolic field, but it is strongly affected by the meteorological noise and, in case of cloud coverage of the framed area, it does not work at all. Moreover, with thermal imaging it is possible measuring only the surface temperature of rocks inside a LTF, but not vertical thermal gradients. Direct measurements are not affected by these problems but are limited to a single point, whose measure could be strongly conditioned by site effects. For this reason, the choice of an adequate number of stations and of the right places where installing them is of crucial importance for ensuring a good performance of the monitoring system. In the following discussion attention will be focused on direct measurement systems, giving some suggestions about mounting settings for ensuring the maximum possible duration of the system and reliability of acquired data. Figure 2 illustrates a typical setting of a probe for measuring temperature along a soil vertical profile.

As shown in the picture, cables and probes are cased into plastic pipes for ensuring the best possible protection from corrosion and electrical insulation: it should be taken in mind that active volcanoes are places preferred by lightnings, thus the electrical contact between instruments and the soil should be avoided as most as possible. The other important element illustrated in Fig. 2 is the position of the thermal probes, at the end of the horizontal arms departing from the vertical pipe: this arrangement ensures that the whole system affects at the less possible extent the heat flux along the measured vertical profile.

The picture in Fig. 3 illustrates a typical data acquisition and transmission system adopted in LTF temperature measurements, composed of a datalogger (the lower box on the metallic pole) for the local acquisition of data and a Iridium satellite system for their transmission to remote acquisition centres. The system is self-powered, by 4 alkaline $1.5 \mathrm{~V} \mathrm{AA}$ batteries for the dataloggers (about 1.5 years of autonomy with 4 temperature sensors at an acquisition rate of a measure per hour) and a solar-recharged battery for the transmission unit (both battery and solar panel enclosed in the waterproof, 


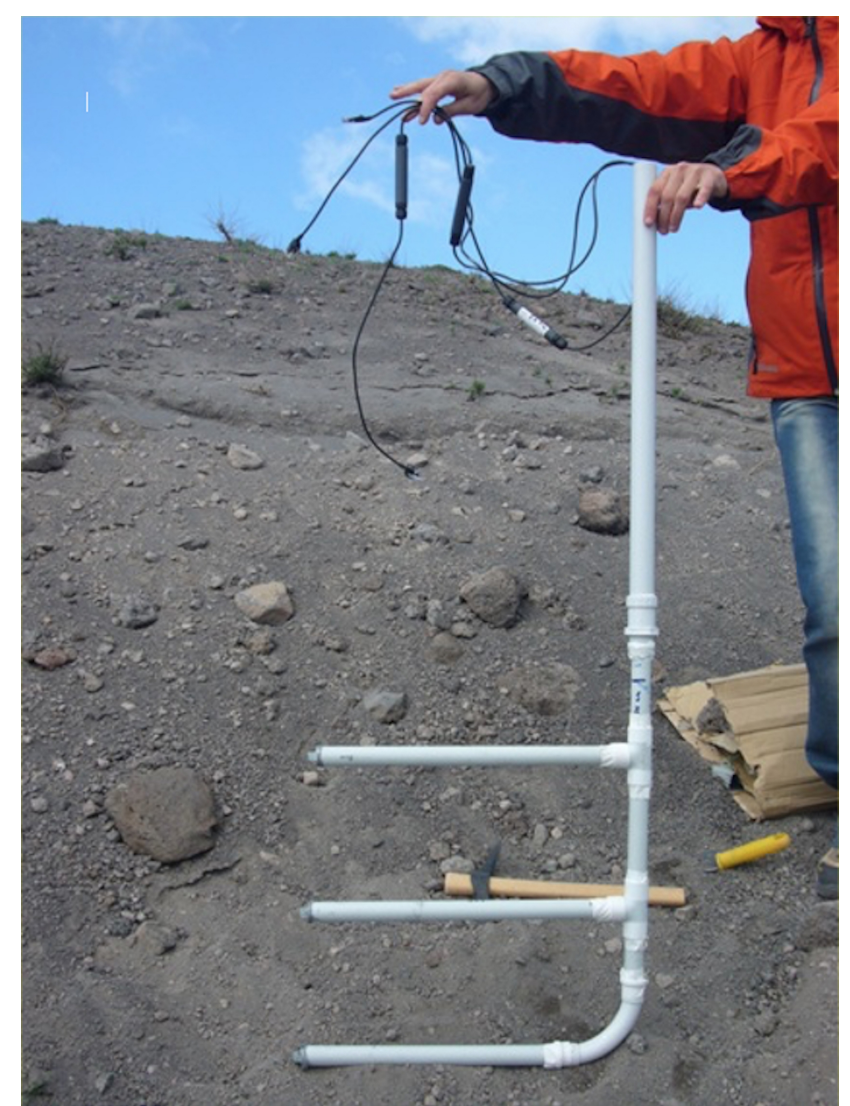

Figure 2. A typical mounting arrangement for a 3-depths LTF temperature probe.

transparent box of the transmission unit). The whole system has a weight of few kilograms, allowing its transportation in a backpack, thus permitting its installation also in remote localities not served by roads.

What is really important for ensuring a successful data acquisition in a LTF is the right positioning of the system inside the fumarolic field, as illustrated in Fig. 4. Since the maximum temperature of a LTF is buffered by the boiling temperature of water (WBT) at the vent elevation, it is not a good idea installing the station too close to the areas showing the highest temperatures (right branch of the curve in Fig. 4): if these are too close to WBT, also little vapor flux increments could elevate the measured temperature to WBT, saturating the signal. Vice-versa, if the station is installed in a marginal location (left branch of the curve), the measured temperatures will be too close to the ambient ones and then seriously affected by the hydro-meteorological noise (solar radiation, rainfalls or nightly condensation of atmospheric humidity). The ideal position is not too close not too far, i.e. in the area where the spatial temperature gradient is high, and consequently the same the expected time gradient (central portion of the curve in Fig. 4). The general principle is that the space temperature distribution in a fumarolic field is a resume of

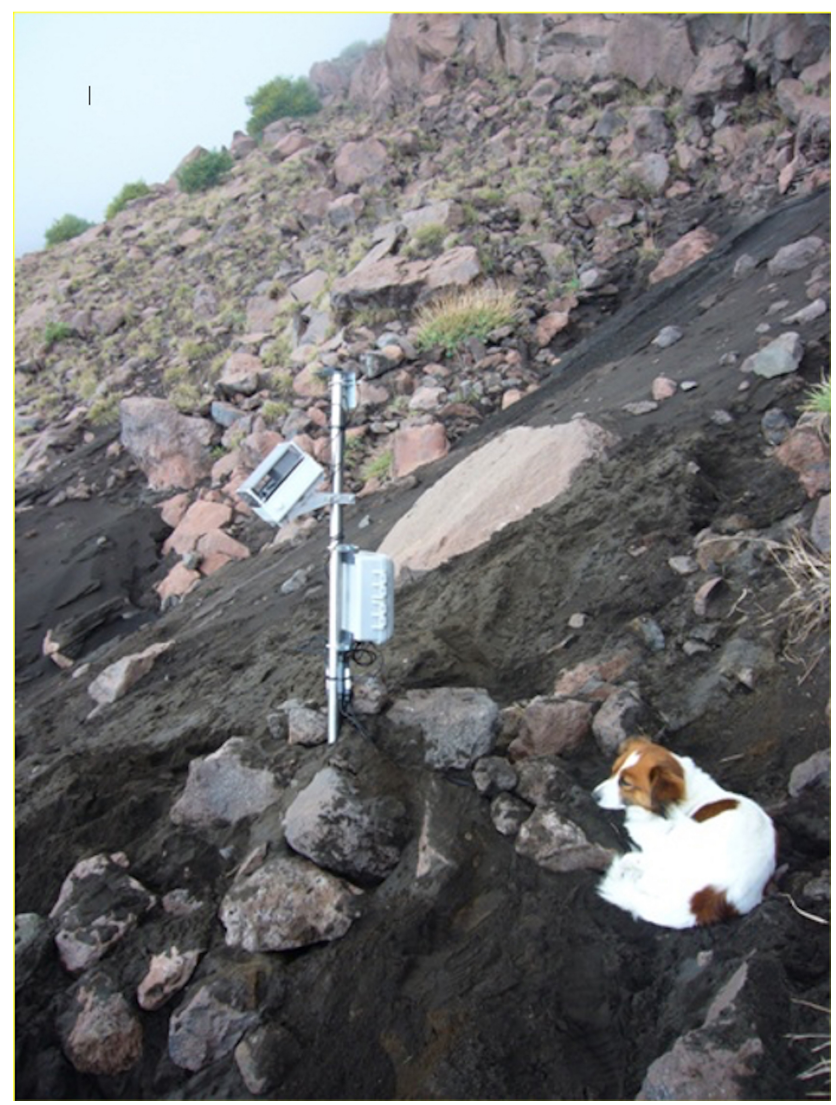

Figure 3. A typical LTF temperature monitoring station, selfpowered with solar-recharged batteries and equipped with an Iridium satellite data transfer system, installed on the SW flank of Stromboli volcano.

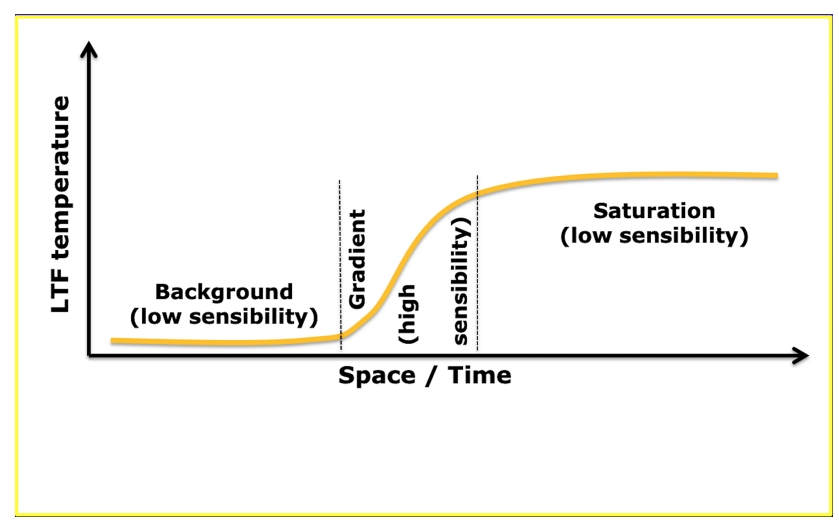

Figure 4. Space/time sensibility of a LTF to temperature changes.

what could be its time evolution: according to this, the ideal location for a measuring site is where soil temperature at $30 \mathrm{~cm}$ of depth is about $45-50^{\circ} \mathrm{C}$, a value as high as to certainly exceed the maximum temperature due to solar heating in summer but as lower as WBT $\left(100^{\circ} \mathrm{C}\right.$ at sea level) to ensure the maximum upgoing dynamic to the thermal signal. 


\section{A brief overview on case histories from Italian volcanoes}

Hereafter a brief overview on some papers focused on the application of this methodology to the study of Italian volcanoes is reported.

\subsection{Vulcano Island}

Vulcano island in the Aeolian archipelago, last erupted in 1888-1890 from la Fossa cone, and since then in a state of intense fumarolic activity, has been since the early 1980s an ideal playground for experimenting the most various techniques of volcanic surveillance, including LTF monitoring. Various researches were based on thermal imagery of the fumarolic field of la Fossa cone (Harris and Stevenson, 1997; Harris and Maciejewski, 2000; Harris et al., 2009, 2012), producing spatial data in the form of non-geocoded pictures taken from the ground. Schöpa et al. (2011) elaborated a georeferenced thermal image mosaic, supported by GPS based ground control points. Other works by Revil et al. (2008) and Barde-Cabusson et al. (2009) produced general thermal maps of the fumarolic field based on direct measures at $30 \mathrm{~cm}$ depth, following radial profiles crossing la Fossa cone. More recently, Madonia et al. (2016) presented data on the distribution of thermally anomalous areas at la Fossa cone, highlighting the role of the diffuse rock coating of hydrothermal origin, covering large portions of the cone, in controlling fluid venting into the atmosphere, and consequently the behaviour of the fumarolic field.

Many other works were concerned with temporal variations of LTF and their relationship with seismic and volcanic activity. Among these, the paper from Aubert et al. (2008) investigated variation in the thermal regime of LTF in the period 1996-2004, evidencing two temperature increases: the first one in November 1998, related to a seismic crisis, and a second one in November 2004, induced by the degassing crisis that affected for some years this system since the second half of 2004. A later work from Cannata et al. (2011) gave new insights on the relationship between these thermal anomalies and volcano-seismic activity. Madonia et al. (2013a) discussed data acquired in a LTF located on the NE flank of la Fossa cone, discriminating among anomalies associated to local seismic activity (16 August $2010 \mathrm{Li}-$ pari earthquake), teleseisms (11 March 2011 Sendai-Honshu Japan earthquake) and volcanic degassing crises (September 2009).

\subsection{Stromboli Island}

De Gregorio et al. (2007) analysed contemporary data of total dissolved gas pressure, measured in the coastal aquifer of Stromboli, and temperature of the summit fumarolic field, in the period comprised between March and October 2006. They recorded several contemporary anomalies of the two parameters, which were interpreted as transients driven by changes in the degassing style of the volcano, with particular reference to the partition ratio of the volcanic fluids between the conduit, the summit fumarolic field and the coastal aquifer. These transients were related to both earthquakes and major explosions.

A later study by Madonia and Fiordilino (2013) proposed a theoretical electric circuital model for describing these transients, applying the method to the analysis of a data series from 2006 to 2010, which included the 2007 Stromboli eruption.

This study produced inferences about the long- and shortterm evolution of the volcanic system, which include shortterm (days) precursors of fracturing driven by dyke intrusions. Calvari et al. (2014) analysed data from a peripheral fumarole, located at about $400 \mathrm{~m}$ of altitude along the Vallonazzo tectonic lineament, retrieving information on magma migration from the deeper to the shallower portions of the magmatic feeding system of the volcano.

\subsection{Mt. Etna}

Madonia et al. (2013b) presented two different thermal LTF datasets acquired in two stations located in the summit area of Mount Etna: the first one, from October 2007 to November 2009, included an effusive eruption, the second one, from November 2011 to June 2012, characterized by fire fountains and lava flows. These authors detected a huge increase in LTF temperature that followed the onset of the 2008-2009 eruption; they interpreted the absence of relevant anomalies preceding the eruption as a sign of the rapid ascent of the magma feeding the eruptive fracture. Other anomalies were recorded between March and April 2012, highlighting the intrusion of a new batch of magma in the conduits of the southeast crater.

Diliberto et al. (2018) measured from September 2009 to September 2012 vertical temperature profiles close to an eruptive fissure, formerly active in 2002 , located $4 \mathrm{~km} \mathrm{NNE}$ from the central craters of Mt. Etna. They observed temperature changes related to variations of eruptive rates, from the new SE crater, between January 2011 and April 2012, interpreted as the response to the structural weakness state of the volcanic edifice.

\subsection{Mt. Vesuvius}

Two papers by Madonia et al. (2008) and Cusano et al. (2013) presented seismic, LTF and hydrological data from Mt. Vesuvius to characterize the present-day activity of this volcano. The aim was to study the correlations between seismic activity (both of volcanic and tectonic origins) and fumarolic fluid circulation in the period 2005-2011. The main event recorded was a very shallow earthquake occurred in August 2005, and preceded by a huge anomaly in a LTF located on the Gran Cono crater rim, which was interpreted as related to fluid-driven rock fracturing. This anomaly was 
followed by an anomalous behaviour of the thermal signal, which lasted for more than one year. More in general, seismicity rate and energy release slight variations were accompanied by changes in LTF temperatures, remarking the reactivity of the fumarolic field to seismic strain.

\section{Conclusions}

The theoretical model of heat transfer processes in Low Temperature Fumaroles (LTF) illustrated in this work clarifies that, due to the difficulty in distinguishing between their conductive and convective components, effective heat flux calculations appear unreliable. In spite of this, temperature anomalies recorded in LTF are very useful, even if qualitative, proxies of change in the activity state of the monitored volcanoes.

The case histories from Italian volcanoes (Vulcano, Stromboli, Mt. Etna, Mt. Vesuvius) here discussed remark that the continuous monitoring and mapping of LTF give useful insights on different phenomena, as upward movements of magma inside the feeding systems, fracturing and dyke intrusions, degassing anomalies driven by seismicity both of volcanic and tectonic origins.

The abovementioned considerations, further supported by the simplicity and money-sparing of the LTF thermal monitoring systems, make this parameter a useful and convenient tool in the developing of volcanic surveillance programs.

Data availability. No data sets were used in this article.

Competing interests. The author declares that there is no conflict of interest.

Special issue statement. This article is part of the special issue "Understanding volcanic processes through geophysical and volcanological data investigations: some case studies from Italian sites (EGU2019 GMPV5.11 session, COV10 S01.11session)". It is a result of the 10th edition of Cities on Volcanoes (CoV10) IAVCEI conference, Naples, Italy, 2-7 September 2018.

Review statement. This paper was edited by Mariarosaria Falanga and reviewed by two anonymous referees.

\section{References}

Aubert, M., Diliberto, I. S., Finizola, A., and Chébli, Y.: Double origin of hydrothermal convective flux variations in the Fossa of Vulcano (Italy), Bull. Volcanol., 70, 743-751, https://doi.org/10.1007/s00445-007-0165-y, 2008.

Badalamenti, B., Chiodini, G., Cioni, R., Favara, R., Francofonte, S., Gurrieri, S., Hauser, S., Inguaggiato, S., Italiano, F., Magro,
G., Nuccio, P.M., Parello, F., Pennisi, M., Romeo, L., Russo, M., Sortino, F., Valenza, M., and Vurro, F.: Special field workshop at Vulcano (Aeolian Islands) during summer 1988: geochemical results, Acta Vulcanol., 1, 223-228, 1991.

Barde-Cabusson, S., Finizola, A., Revil, A., Ricci, T., Piscitelli, S., Rizzo, E., Angeletti, B., Balasco, M., Bennati, L., Byrdina, S., Carzaniga, N., Crespy, A., Di Gangi, F., Morin, J., Perrone, A., Rossi, M., Roulleau, E., Suski, B., and Villeneuve, N.: New geological insights and structural control on fluid circulation in $\mathrm{La}$ Fossa cone (Vulcano, Aeolian Islands, Italy), J. Volcanol. Geoth. Res., 185, 231-245, 2009.

Bukumirovic, T., Italiano, F., and Nuccio, P. M.: The evolution of a dynamic geological system: the support of a GIS for geochemical measurements at the fumarole field of Vulcano, Italy, J. Volcanol. Geoth. Res., 79, 253-263, https://doi.org/10.1016/S03770273(97)00032-2, 1997.

Calvari, S., Bonaccorso, A., Madonia, P., Neri, M., Liuzzo, G., Salerno, G., Behncke, B., Caltabiano, T., Cristaldi, A., Giuffrida, G., La Spina, A., Marotta, E., Ricci, T., and Spampinato, L.: Major eruptive style changes induced by structural modifications of a shallow conduit system: the 2007-2012 Stromboli case, Bull. Volcanol., 76, 841, https://doi.org/10.1007/s00445-014-0841-7, 2014.

Cannata, A., Diliberto, I. S., Alparone, S., Gambino, S., Gresta, S., Liotta, M., Madonia, P., Milluzzo, V., Aliotta, M., and Montalto, P.: Multiparametric Approach in Investigating VolcanoHydrothermal Systems: the Case Study of Vulcano (Aeolian Islands, Italy), Pure Appl. Geophys., 169, 167-182, https://doi.org/10.1007/s00024-011-0297-z, 2011.

Cusano, P., Petrosino, S., Madonia, P., and Federico, C.: Seismic activity and thermal regime of low temperature fumaroles at Mt. Vesuvius in 2004-2011: distinguishing among seismic, volcanic and hydrological signals, Ann. Geophys. Italy, 56, 4, https://doi.org/10.4401/ag-6446, 2013.

De Gregorio, S., Madonia, P., Gurrieri, S., Giudice, G., and Inguaggiato, S.: Contemporary total dissolved gas pressure and soil temperature anomalies recorded at Stromboli volcano (Italy), Geophys. Res. Lett., 34, L08301, https://doi.org/10.1029/2007GL029578, 2007.

Diliberto, I. S., Gagliano Candela, E., Morici, S., Pecoraino, G., Bellomo, S., Bitetto, M., and Longo, M.: Changes in heat released by hydrothermal circulation monitored during an eruptive cycle at Mt. Etna (Italy), Bull. Volcanol., 80, 31, https://doi.org/10.1007/s00445-018-1198-0, 2018.

Harris, A. J. L. and Maciejewski, A. J. H.: Thermal surveys of the Vulcano Fossa fumaroles field 1994-1999: evidence for fumarole migration and sealing, J. Volcanol. Geoth. Res., 102, 119147, 2000.

Harris, A. J. L. and Stevenson, D. S.: Magma budgets and steadystate activity of Vulcano and Stromboli, Geophys. Res. Lett., 24, 1043-1046, 1997.

Harris, A. J. L., Lodato, L., Dehn, J., and Spampinato, L.: Thermal characterization of the Vulcano fumarole field, Bull. Volcanol., 71, 441-458, 2009.

Harris, A., Alparone, S., Bonforte, A., Dehn, J., Gambino, S., Lodato, L., and Spampinato, L.: Vent temperature trends at the Vulcano Fossa fumarole field: the role of permeability, Bull. Volcanol., 74, 1293-1311, 2012. 
Incropera, F. P. and Dewitt, D.: Introduction to heat transfer, Wiley, New York, USA, 2002.

Madonia, P. and Fiordilino, E: Time variability of lowtemperature fumaroles at Stromboli island (Italy) and its application to volcano monitoring, Bull. Volcanol., 75, 776, https://doi.org/10.1007/s00445-013-0776-4, 2013.

Madonia, P., Federico, C., Cusano, P., Petrosino, S., Aiuppa, A., and Gurrieri, S.: Crustal dynamics of Mount Vesuvius from 1998 to 2005: Effects on seismicity and fluid circulation, J. Geophys. Res., 113, B05206, https://doi.org/10.1029/2007JB005210, 2008.

Madonia, P., Cusano, P., Diliberto, I. S., and Cangemi, M.: Thermal anomalies in fumaroles at Vulcano island (Italy) and their relationship with seismic activity, Phys. Chem. Earth, 63, 160-169, https://doi.org/10.1016/j.pce.2013.06.001, 2013a.

Madonia, P., Rizzo, A. L., Diliberto, I. S., and Favara, R.: Continuous monitoring of fumarole temperatures at Mount Etna (Italy), J. Volcanol. Geoth. Res., 257, 12-20, https://doi.org/10.1016/j.jvolgeores.2013.03.001, 2013b.

Madonia, P., Cangemi, M., Costa, M., and Madonia, I.: Mapping fumarolic fields in volcanic areas: A methodological approach based on the case study of La Fossa cone, Vulcano island (Italy), J. Volcanol. Geoth. Res., 324, 1-7, 2016.
Madonia, P., Cangemi, M., Olivares, L., Oliveri, Y., and Tommasi, P.: Shallow landslide generation at La Fossa cone, Vulcano island (Italy): a multidisciplinary perspective, Landslides, 16, 921-935, https://doi.org/10.1007/s10346-019-01149-z, 2019.

Petrosino, S., Cusano, P., and Madonia, P.: Tidal and hydrological periodicities of seismicity reveal new risk scenarios at Campi Flegrei caldera, Sci. Rep.-UK, 8, 13808, https://doi.org/10.1038/s41598-018-31760-4, 2018.

Revil, A., Finizola, A., Piscitelli, S., Rizzo, E., Ricci, T., Crespy, A., Angeletti, B., Balasco, M., Barde Cabusson, S., Bennati, L., Bolève, A., Byrdina, S., Carzaniga, N., Di Gangi, F., Morin, J., Perrone, A., Rossi, M., Roulleau, E., and Suski, B.: Inner structure of La Fossa di Vulcano (Vulcano Island, southern Tyrrhenian Sea, Italy) revealed by high resolution electric resistivity tomography coupled with self-potential, temperature, and $\mathrm{CO}_{2}$ diffuse degassing measurements, J. Geophys. Res., 113, B07207, https://doi.org/10.1029/2007JB005394, 2008.

Schöpa, A., Pantaleo, M., and Walter, T. R.: Scale-dependent location of hydrothermal vents: stress field models and infrared field observations on the Fossa Cone, Vulcano Island, Italy, J. Volcanol. Geoth. Res., 203, 133-145, 2011. 